\title{
Retórica e poder: representações do discurso empresarial em textos multimodais nos media
}

Alcina Maria Pereira de Sousa

- Doutorada em Letras, na especialidade de Linguística Inglesa, na área da linguística aplicada

- Licenciada em Línguas e Literaturas Modernas - Estudos Ingleses e Alemães

- Faculdade de Letras da Universidade de Lisboa

- Profissionalização em Serviço na Faculdade de Psicologia e Ciências da Educação da Universidade de Lisboa

- Professora Auxiliar no Departamento de Estudos Anglísticos e Germanísticos (DEAG) da Universidade da Madeira

- Regente das cadeiras de Linguística Inglesa Aplicada (ao ramo empresarial), Análise Textual, Expressão e Comunicação do Inglês, Língua Inglesa, Língua Inglesa Aplicada (Turismo e Lazer, Técnico-Científico)

- Directora do $1^{\circ}$ Ciclo em Estudos Ingleses e Relações Empresariais (2008-2009) e das Licenciaturas em Estudos Anglo-Germanísticos, em Línguas e Literaturas Modernas - Estudos Ingleses e Alemães, e do Plano Novo em Estudos Portugueses e Ingleses (2003-2008)

- Tem desenvolvido pesquisa e publicado na área da língua pela literatura, estilística, análise do discurso, e da leitura crítica, com o recurso à corpus linguistics aplicado à: investigação da leitura, estudos de literacia, análise do discurso empresarial e urbanístico, tratamento e análise de inquéritos

- Professora investigadora do Centro de Estudos Anglísticos da Universidade de Lisboa (CEAUL-Portugal)

- Membro do comité científico e do conselho editorial da Associação de Investigação Científica do Atlântico (AICA)

- Membro da Poetics and Linguistics Association (PALA), ramo estilística, sendo também PALA Ambassador (desde 2008)

- Consultora linguística (discurso especializado) em artigos científicos com arbitragem internacional

- Professora visitante convidada em várias instituições internacionais (Picture Book Museum Burg Wissem, em Troisdorf, na Alemanha; Universidade de Pádua, Universidade Estadual do Maranhão, no Brasil; Pontifícia Universidade Católica de São Paulo, no Brasil, Universidade de Pardubice, na República Checa)

- ninita@netmadeira.com 
Resumo

A análise multidisciplinar de alguns excertos das revistas The Economist (de circulação internacional), e em contraste, Visão e Sábado (no espaço lusófono), visa promover uma reflexão, embora sumária, sobre a natureza da representação e do impacto do discurso empresarial e de negócios, em textos jornalísticos. Evidenciamos o recurso a estratégias linguísticas, discursivas e estilísticas frequentes, nomeadamente ao inglês como língua franca, à literariedade e à criatividade, implícitas em metáforas visuais, recorrentes em textos multimodais. Estes contribuem para o envolvimento dos leitores / cidadãos, num crescendo emocional, na construção de sentidos nos e para além dos textos no contexto discursivo e social, determinando uma forma particular de percepcionar temáticas desconhecidas em domínios interdiscursivos.

PALAVRAS-CHAVE: TEXTO MULTIMODAL • RETÓRICA • RECURSOS ESTILÍSTICOS • DISCURSO EMPRESARIAL NOS MEDIA

Abstract

The multidisciplinary analysis of some excerpts from magazines like The Economist (of international circulation), and in contrast, Visão and Sábado (in the Lusitophone context), aims at promoting some reflection, albeit brief, about the kind of representation and impact of entrepreneurial and business discourse on media discursive practices. It evidences the resorting to frequent linguistic, discursive and stylistic strategies, notably to English as a lingua franca, literariness and creativity, implicit in visual metaphors, which are recurring in multimodal texts. They contribute to the readers' / citizens' involvement, in an emotional crescendo, with the construction of meaning and going beyond the texts in the discursive and social context, determining a particular way of perceiving unfamiliar topics in inter-discursive domains.

KEYWORDS: MULTIMODAL TEXT • RHETORIC • STYLISTIC DEVICES • MEDIA BUSINESS DISCOURSE

Resumen

El análisis multidisciplinar de algunos extractos de las revistas The Economist (de circulación internacional), y, en contraste, Visão y Sábado (en el espacio lusófono), se propone reflexionar, de forma sumaria, sobre la naturaleza y el impacto del discurso empresarial y de negocios en textos periodísticos. Resaltamos las estrategias lingüísticas, discursivas y estilísticas frecuentes; en especial, el uso del inglés como una lengua franca, la literalidad y la creatividad, implícitas en metáforas visuales, recurrentes en textos multimodales. Estos contribuyen a involucrar a los lectores/ciudadanos, en un crescendo emocional e inculcan una forma particular de captar temáticas desconocidas en dominios interdiscursivos.

PALABRAS CLAVE: TEXTO MULTIMODAL • RETÓRICA • RECURSOS ESTILÍSTICOS • DISCURSO EMPRESARIAL EN LOS MASS MEDIA 
$\mathrm{N}^{2}$ a contemporaneidade, e com o advento da sociedade da informação, temáticas, tais como as flutuações de capital, o mercado financeiro, ou as taxas únicas, deixaram de fazer parte do domínio exclusivo de especialistas, pela necessidade imperiosa do envolvimento dos cidadãos à escala global. Tal é corroborado por Kjaer e Slaatte, em Mediating business: the expansion of business journalism (2007, p. 11), segundo os quais as considerações econômicas se afiguram como um factor primordial em todas as decisões, tanto no domínio privado como no público, e a mediatização da esfera econômica são, portanto, naturais [trad. nossa]. Concomitantemente, constatam-se novas formas de representação e cobertura de assuntos econômicos na imprensa escrita. A propósito da crescente mediatização das relações sociais, refere Conceição (2008, p. 7), "os indivíduos e as coletividades só ganham existência pública nos espaços instituídos pela acção" dos media, nomeadamente a imprensa escrita. No entanto, problematiza o autor, " a forma como a fala do outro é apresentada (ou não) em público interfere nas relações sociais e nos sistemas de conhecimento e crenças."

Com a selecção de alguns artigos de revistas e semanários de circulação internacional, que apresentamos, considerados relevantes para sobre as temáticas em apreço, por exemplo The Economist (em língua inglesa), e Visão e Sábado, de larga circulação no espaço português europeu, pretendemos analisar representações do discurso empresarial ${ }^{1}$ em textos multimodais nos media, dada à forma como colocam desafios na sociedade multicultural internacional, apelando à participação e ao diálogo, todavia incutindo nos leitores / cidadãos uma forma particular de percepcionar (CARTER, 1994, p. 5) as dimensões econômica e empresarial no plano enunciativo. São os seguintes os textos seleccionados, de natureza multimodal, nos quais também é evidente a forma como os elementos, nos modos visual (não-verbal) e verbal, interagem a nível discursivo (GOODMAN et al., 1996, p. 69), bem como o impacto da língua inglesa no discurso empresarial, na imprensa escrita em português, entre outros aspectos a analisar sumariamente neste estudo: "The flat-tax revolution" (The Economist, de 16/04/2005); "Hatfuls of dollars: Rich government, poor people" (The Economist, de 16/04/2005); "American lawmakers take aim at fat cats' bonuses, and other news" (Economist.com, de 23/03/2009); "Temperatura da bolsa" (Visão, de 17/04/08, p. 74); "Negócios instantâneos" (Sábado, de 03-09/04/2008, p. 78); "Remunerações. Os prémios que são pagos aos executivos de topo" (Sábado, de 03/04/2008, p. 74-77); e "Uma nomeação natural” (Visão, de 17/04/2008, p. 50). A análise contrastiva poderá também desambiguar uma outra questão, porém para além do âmbito deste estudo, nomeadamente a da identificação dos discursos dominantes relativos à identidade nacional supranacional, bem como o de

1 A ambivalência do termo "empresarial" ( $\longrightarrow$ "enterprise", em inglês) segundo Fairclough (1995, p. 113), decorre da potencial significativo do mesmo que se reporta a: "actividade" ( $\longrightarrow$ "activity"), "qualidade" $(\longrightarrow$ "quality") e "negócio(s)" ( $\longrightarrow$ "business"). Na verdade encontramos uma diversidade de títulos para a rubrica "business" / "negócios", quer na imprensa de expressão inglesa, quer na de expressão portuguesa, por exemplo, "business and finance" (The Economist), "business and technology" (Time), "dinheiro" (Sábado), "economia" (Visão), "empresas" (Exame Angola), "empresas e negócios" (África 21). 
cidadania, disseminados pelos media neste domínio, sendo, todavia, necessário um corpus mais vasto de textos.

Pretendemos, deste modo, alargar o entendimento sobre as estratégias argumentativas e discursivas na construção de conteúdos mediáticos, pelo enfoque na organização simbólica da interacção entre os cidadãos e as comunidades discursivas. Em relação à organização simbólica e à natureza das relações de poder activadas a nível discursivo, Fairclough (1992, p. 51) afirma que estas são pouco claras, pois são mediadas pelos detentores de poder, mais especificamente as instituições e a população. A acepção de poder insere-se na linha de Foucault ("knowldege is power"), segundo a qual os cidadãos são mais controlados pelo discurso especializado, organizado em comunidades discursivas denominadas de "regimes of truth" (CAMERON et al., 1999, p. 141). É, igualmente, nosso objectivo discutir e ilustrar as possibilidades de uma abordagem estilística (CARTER; NASH, 1993; CARTER, 1994, p. 5) aplicada à análise de textos de natureza multimodal para um melhor entendimento da cidadania mediatizada.

A proposta de uma abordagem multidisciplinar e interdisciplinar (estilística e discursiva), aplicada à análise da linguagem em uso, em práticas discursivas no domínio empresarial e econômico nos media, tem como objectivo ilustrar as possibilidades de uma abordagem multidisciplinar para uma melhor interpretação das relações de poder activadas a nível discursivo. Para além disso, visa analisar o seu potencial significativo pelo enfoque em estratégias linguísticas, discursivas e estilísticas frequentes, nomeadamente: a alternância de modos discursivos (discurso oral e escrito), a estrutura da narrativa, o estilo dialogante (como se tratasse de uma conversa informal versus diálogo institucional), o uso criativo de idiomatismos, a lexicalização, transformação e substituição, a língua franca, a literariedade e a criatividade, implícitas em metáforas visuais e imagens, recorrentes em textos multimodais, que activam as relações de poder a nível discursivo, subjacente ao agir comunicativo.

\section{Abordagem conceptual}

Num artigo, publicado na ESSE, em 2005, Macleod (2005, p. 62) argumenta que a descrição da linguagem em uso beneficia uma análise linguística e estilística, na medida em que recorre a métodos e pressupostos desenvolvidos pela linguística na descrição e interpretação do potencial significativo da linguagem em uso, quer na sua função estética, quer comunicativa (MACLEOD, 2005, tradução nossa), ou segundo Carter e Long (1991, p. 9), a linguagem nas suas funções referencial e ideacional, num contínuo significativo, seguindo o modelo teórico de Jakobson (1960, p. 350-377). A perspectiva da estilística contemporânea decorrente (cf. CARTER; SIMPSON, 2004; STOCKWELL; LAMBROU, 2007; SHORT, 2008; entre outros) envolve um estudo multidisciplinar pela identificação de escolhas linguísticas (morfológicas, lexicais e sintácticas) e dis- 
cursivas, além do recurso a técnicas mais comuns na linguística computacional ${ }^{2}$ (BIBER et al., 1998), nomeadamente a linguística de corpora ${ }^{3}$ (BAKER, 2006; MAHLBERG apud STOCKWELL; LAMBROU, 2009, p. 19-31). É nosso objectivo demonstrar que os textos em estudo evidenciam estruturas linguísticas e estilísticas coadjuvadas pela componente discursiva da linguagem não-verbal/ visual (CLARK; ZYNGIER, 2003, p. 342), subjacentes à dimensão informativa, persuasiva e estética, que influenciam o alocutário/leitor na sua decisão (cf. FONSECA, 1992) determinando uma forma particular de percepcionar (CARTER, 1994, p. 5) as temáticas respeitantes à comunidade discursiva em foco.

A estilística mantém, igualmente, uma estreita relação com a retórica clássica, sua predecessora, pelo facto de se reportar ao, tal como define Meyer (apud CARRILHO, 1994, p. 31-69), "estudo do discurso ou as técnicas de persuasão e até de manipulação". Distinguimos três níveis de análise complementares: I) a análise do conteúdo proposicional no plano enunciativo (ethos); II) do discurso e (Ibid.) "de efeitos de sentido", nomeadamente o literal e o figurado, o dito e o "implícito conotado pelo enunciado ou a inferir da enunciação" (logos); III) e do "discurso multimodal” (KRESS; LEEUVEN, 2001), que compreende o potencial significativo da linguagem verbal e não-verbal pelo apelo ao envolvimento emocional e cognitivo do alocutário (pathos).

No processo interpretativo das escolhas linguísticas e discursivas interagem vários planos de análise (Ver Figura 1), nomeadamente, léxico-semântica, sintáctica e pragmática ${ }^{4}$ em lato sensu (HOEY, 2005, p. 163), atendendo a que, defende Hoey (2005, p. 163), "there seems to be two fundamental dynamic processes involved in the production of spoken and written interaction". O primeiro diz respeito ao "lexical priming" na medida em que, como explica o linguista, "every lexical choice starts off a series of options and predilections... in any situation in which the speaker has been primed to perform". A segunda concerne o processo discursivo que envolve tomadas de decisão quanto ao

2 Na sua antologia de textos, Sampson e McCarthy $(2004$, p. 1) consideram crucial que se defina o termo "corpus linguistics" no paradigma contemporâneo de análise de corpora (i.e., "a collection of specimens of a language as used in real life, in speech or writing, selected as a sizeable 'fair sample' of the language as a whole or of some linguistic genre") pelo facto dos métodos e metodologias de pesquisa dependerem muito significativamente da tecnologia computacional: (1) corpus de textos digitalizados, (2) programa informático (por exemplo Word Smith Tools, Mono Conc, Concapp, entre outros) que apresenta automaticamente os contextos de ocorrência das palavras pesquisadas, permitindo não só a sua quantificação, mas também a análise comparativa do (PARTINGTON, 1998, p. 65) "conceptual meaning of words and the connotational significance of lexis" no corpus e corpora.

3 Corpus (corpora, no plural), tal como é definido por Sinclair (2004), abarca uma "collection of pieces of language text, in electronic form, selected according to external criteria to represent, as far as possible, a language or language variety as a source of data for linguistic research."

4 Hoey explicita o modo como a análise de corpora é enriquecida pela pragmática, a qual denomina de (1997, p. 8-9) "pragmalinguistic" no âmbito da análise da modalidade, a saber: "co-occurrence is examined in terms of speaker meaning and context of utterance. The nuances introduced by particular modaladverb associations and the influences that motivate their selection offer further insights into how modaladverb collocations may be accounted for and eventually formulated." 
conteúdo proposicional, género discursivo, domínio/domínios (interdiscursividade), interlocutores, além de, Hoey (2005, p. 163) acrescenta, "características específicas do contexto que cumulativamente dão conta, e contribuem para o que tem sido tradicionalmente denominado da sintaxe, semântica, pragmática e elementos discursivos da língua” [tradução nossa].

Figura 1. Interacção de níveis de significação - análise estilística

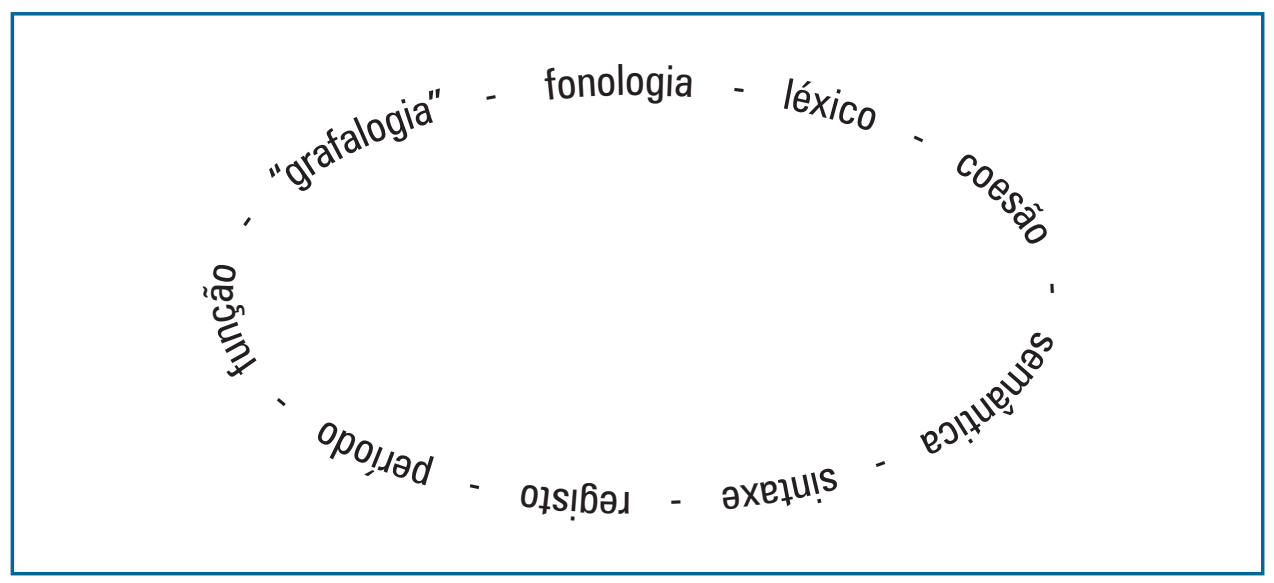

Estão, assim, em foco três níveis de análise que se complementam: I) análise linguística de níveis de significação para explicitação da "objectivitividade" (SHORT, 1993) e da interacção dos leitores com a linguagem em uso e estilo (VERDONK, 1993, p. 7) na comunidade discursiva; II) análise das representações, atitudes e expectativas do locutor - alocutário no plano enunciativo, designadamente o ponto de vista, referência e coesão e coerência; e III) o contributo da semiótica social, nomeadamente a análise da gramática do texto visual. Estes elementos reflectem a natureza social do entrosamento do discurso empresarial no discurso mediático. Aliás, seguindo Kress (1997, p. 382), a linguagem, como um sistema semiótico, "constitutes a set of resources, organized by larger cultural values and social contingencies, and deployed and remade innovatively in the making of always novel signs."

De entre os níveis de significação, para explicitação da construção de sentidos e interacção dos leitores com a linguagem em uso em comunidades interdiscursivas (cf. MAINGUENEAU, 1997; FAIRCLOUGH, 1992), seleccionaremos apenas, neste estudo: os elementos paratextuais (GENETTE, 1997), tais como os títulos, subtítulos, ilustrações, entre outros, denominados por "grafologia" (WALES, 2001, p. 182-183), assim como as escolhas léxico-semânticas e discursivas (tais como, a referência pronominal, a coerência intersemiótica, a função e o registo). A interpretação dos signos deverá ser feita à luz dos sistemas semióticos (KRESS; LEEUVEN, 1996). 
Os leitores e os textos multimodais em domínios interdiscursivos, empresarial e econômico/político, nos media: perspectiva contrastiva (The Economist, Visão e Sábado)

Pela complexidade de comunidades discursivas que se cruzam na panóplia de práticas discursivas na imprensa escrita, no escopo deste estudo, e hierarquizadas no plano enunciativo, a análise linguística dos textos econômico/empresarial constitui uma tarefa complexa. Para além das condicionantes relacionadas com a política editorial de cada revista, e dos respectivos manuais de redacção e de estilo ${ }^{5}$ (daí que sejam denominadas de tecnologias discursivas, na acepção de Fairclough, 1997), refira-se a importância da mediação das próprias instituições jornalísticas em relação às "vozes da sociedade que constituem os espaços públicos” (CONCEIÇÃO, 2008, p.8). Para tal, nos artigos que analisamos sumariamente, nas versões em língua inglesa e portuguesa, observamos o uso frequente de frases simples e compostas, da parataxe (mais próximas do discurso oral), entrecortadas por frases complexas (hipotaxe), e do suporte visual, tratando-se, pois, de textos de natureza multimodal (KRESS; LEEUVEN, 2001). Assim sendo, vários tipos de linguagem, verbal e não verbal, e estratégias discursivas interagem no plano textual, pelo que facilitam a compreensão da mensagem, por vezes pontuada por expressões no domínio especializado, por parte dos leitores.

Ao veicularem informação acerca de comunidades discursivas específicas, por um lado, o discurso mediático e, por outro, o domínio empresarial, econômico e financeiro, os textos multimodais promovem (KRESS, 1997, p. 382) "the potentials of representational and communicational modes". Consequentemente, proporcionam "different kinds of possibilities of human expression and engagement with the world, and through this differential engagement with the world, differential possibilities of development: bodily, cognitively, [and] affectively." (KRESS, 1997, p. 382). Por outras palavras, advoga Jereczek (2002), os textos mediáticos no domínio empresarial e afins têm uma tripla função: pedagógica, estética e informativa.

\section{Escolhas linguístico-discursivas}

Os artigos relacionados com a temática dos impostos são recorrentes nas rubricas empresariais e de economia nas revistas seleccionadas. Destacamos, por exemplo, a reportagem publicada na revista The Economist (de 16/04/2005), intitulada "The flat-tax revolution", que visa informar, formar e persuadir, daí que recorra intencionalmente a uma forma criativa e apelativa, sob a égide de "revolução" ou mesmo "teoria", explícita no título da capa, e mais adiante reiterada como "teoria”, num dos subtítulos. O contexto de ocorrência do 
lexema "flat" ( $\longrightarrow$ plano) $)^{6}$, tal como é apresentado nas linhas de concordância inseridas abaixo ${ }^{7}$, aponta para o potencial significativo da lexia, e o seu uso no domínio especializado, para "flat tax" ( $\longrightarrow$ taxa fixa, única). Os leitores são habilmente conduzidos a descodificar o significado da lexia a partir do contexto de ocorrência, isto é, a nível do sintagma, frase, texto e comunidade discursiva. O processo de descodificação e interpretação é também facilitado pelas múltiplas referências extratextuais (socioculturais, históricas, geográficas, entre outras) e discursivas subjacentes.

É oportuno mencionar que os autores dos artigos em estudo seguem um estilo próprio, patente nos semanários em análise, ao aludirem a um conjunto vasto de referências culturais, registo, período, e estilo, que suscitam no destinatário uma motivação intrínseca pela procura de sentidos. Citemos, por exemplo, as referências endofóricas explícitas nas passagens de: I) "Flat-tax revolution" (Economist, 16/04/2005, p. 64-65); "To the layman, a flat-tax simply means..."; "grind the spirit of the helpless taxpayer"; "As every American knows, their country was founded in the wake of a tax revolt. What most forget is that the so-called 'Boston tea party"”; II) "(...) os melhores corretores deixam o Bear Sterns (...)” (Sábado, 03/04/2009); "Quem esteja familiarizado com outros modelos mais antigos do grupo pode encontrar no Logan (...)” (Visão, de 17/04/2008, p. 78).

Predomina o uso do lexema "flat", como adjectivo no sintagma nominal "flat tax" (coesão lexical), e expandido a "flat-tax revolutionaries", "flat-tax revolution", "flat income tax", "flat rate", e na forma do plural "flat taxis", quando se alude à política de redução das taxas a implementar na América, ou a "flattax systems", visando persuadir os leitores, também contribuintes $(\longrightarrow$ "tax payers"), a terem uma opinião favorável em relação ao imposto único simples e vantajoso: "pure flat tax" (linha 31). A repetição, como recurso estilístico, contribui para que o público leitor, não especializado, memorize e se aproprie do conceito, de forma significativa.

1. to $8.2 \%$ of GDP. In 2002, its flat income tax raised revenues wor

2. worth just $7.2 \%$. Indeed, the flat income tax that generated so

3. s robust revenues owe to its flat income tax? Perhaps less than

4. comes closest to this model. Flat, not low. Nor are flat taxes sy

5. and the take from all taxes, flat or otherwise, consequently imp

6. e of $13 \%$. But Lithuania's 33\% flat rate is too high for some Amer

7. $\mathrm{x}$ than they would under a $25 \%$ flat tax (see chart on page 71 ). Mo

8. But the connoisseur of the flat tax can distinguish several di

60 contexto de ocorrência refere-se ao "concordance string", contendo o lexema cuja extensão é determinada pelo linguista no programa de concordâncias: um número de palavras para a direita e para a esquerda do lexema.

7 Recorremos a um programa de concordâncias, ConcApp Concordance and Word Profiler, versão 4.0 para Windows, a fim de procedermos a uma análise textual, tendo em conta a frequência de palavras, a ocorrência de categorias léxico-semânticas e sintácticas. 
9. ion tax (since in principle a flat tax could take as its base eit

10. W that it could not suggest a flat tax even if it wanted to. This

11. Estonia now plans to cut its flat tax from $26 \%$ to $20 \%$ by 2007 . B

12. roll over the opposition. The flat-tax idea is big enough and sim

13. $t$ the principal virtue of the flat tax is its simplicity. The gov

14. d (largely in vain to date) a flat tax of $30 \%$ on Spanish incomes.

15. ministry also proposed a $30 \%$ flat tax on all personal and corpor

16. n 2001, Russia too moved to a flat tax on personal income. Three

17. s out in principle. Not so. A flat tax on personal incomes combin

18. pay about as much tax under a flat-tax regime as they do under an

19. The flat-tax revolution Fine in theory,

20. e outset. It is true that the flat-tax revolutionaries of central

21. oor are called upon to pay. A flat tax seems to rule this out in

22. poor people. To the layman, a flat tax simply means a single rate

23. Pioneered ha eastern Europe, flat tax systems seem to work becau

24. e of rubles encouraged by the flat tax was more sustained. A care

25. $\mathrm{d}$ to. This is a great pity. A flat tax would not eliminate the $\mathrm{n}$

26. try in Europe to introduce a "flat tax" on personal and corporate

27. ope to introduce a so-called "flat tax", replacing three tax rate

28. f its 2001 reform. Slovakia's flat tax, by contrast, covers both

29. ed $68 \%$. Many advocates of the flat tax, particularly in America,

30. wever. In the year before the flat tax, Russians in the two highe

31. simplest of all. Under a pure flat tax, the taxman takes the same

32. Practical types who said that flat taxes cannot work offer a furt

33. ersonal and corporate income. Flat taxes differ in scope as well

34. ithuania's example might make flat taxes more palatable to the so

35. nt's revenues in the future. Flat taxes on the steppes The most

36. Page 9. Page 3. The case for flat taxes Pioneered ha eastern Eur

37. model. Flat, not low Nor are flat taxes synonymous with low taxe

38. ent varieties. In America the flat taxis associated with a propos

Pelo recurso à comparação de vários sistemas econômicos, subjacente à imagem da mudança ancorada na dimensão histórica e sociocultural do público alvo, o narratário dá-se conta da relevância desta "revolução" (linha 1), pois os cidadãos americanos são apresentados como exemplo por ansiarem a redução dos impostos. Neste contexto, "flatten" ( $\rightarrow$ engomar; reduzir) surge como forma verbal, reiterando a imagem inicial do ferro de engomar exibida na capa do The Economist. De resto, a capa-cartaz na qual se destaca a notícia acerca da taxa única visa não só informar, mas também formar. Os elementos visuais e textuais são apresentados em dimensões ampliadas.

1. atives in America who long to flatten their own country's taxes.

2. On January 1st 2001, Russia flattened and broadened its persona

3. their tax rates as they have flattened them. In 1994, Ukraine's

4. his high rate of VAT, not the flattening of its other taxes, that

5. n 2002. VAT's, of course, the flattest tax of all. It levies a un 
A taxa única ( $\longrightarrow$ "flat-tax") acaba por ser desambiguada na página 63, do exemplar da revista The Economist (de 16/04/2005), na instância definidora da comunidade discursiva, econômica e empresarial, por oposição ao uso do item lexical em registos informais e conhecido pelo grande público falante da língua inglesa. Tal como o narrador refere: "replac[es] three tax rates on personal income, and another on corporate profits, with one uniform rate of $26 \%$. Simplicity itself."

Aliás, a reportagem sobre "the flat-tax revolution" (cf. Figura 2) é caracterizada por uma "forma de apresentação fragmentada, como um mosaico" (GOUAZÉ, 1999, apud MIELNICZUK; PALACIOS, 1999), característica da imprensa escrita, dado que "a forma da escritura se dá através de artigos e títulos distribuídos nas diferentes partes do jornal.” (Ibid).

Figura 2. "The flat-tax revolution", The Economist (de 16/04/2005)

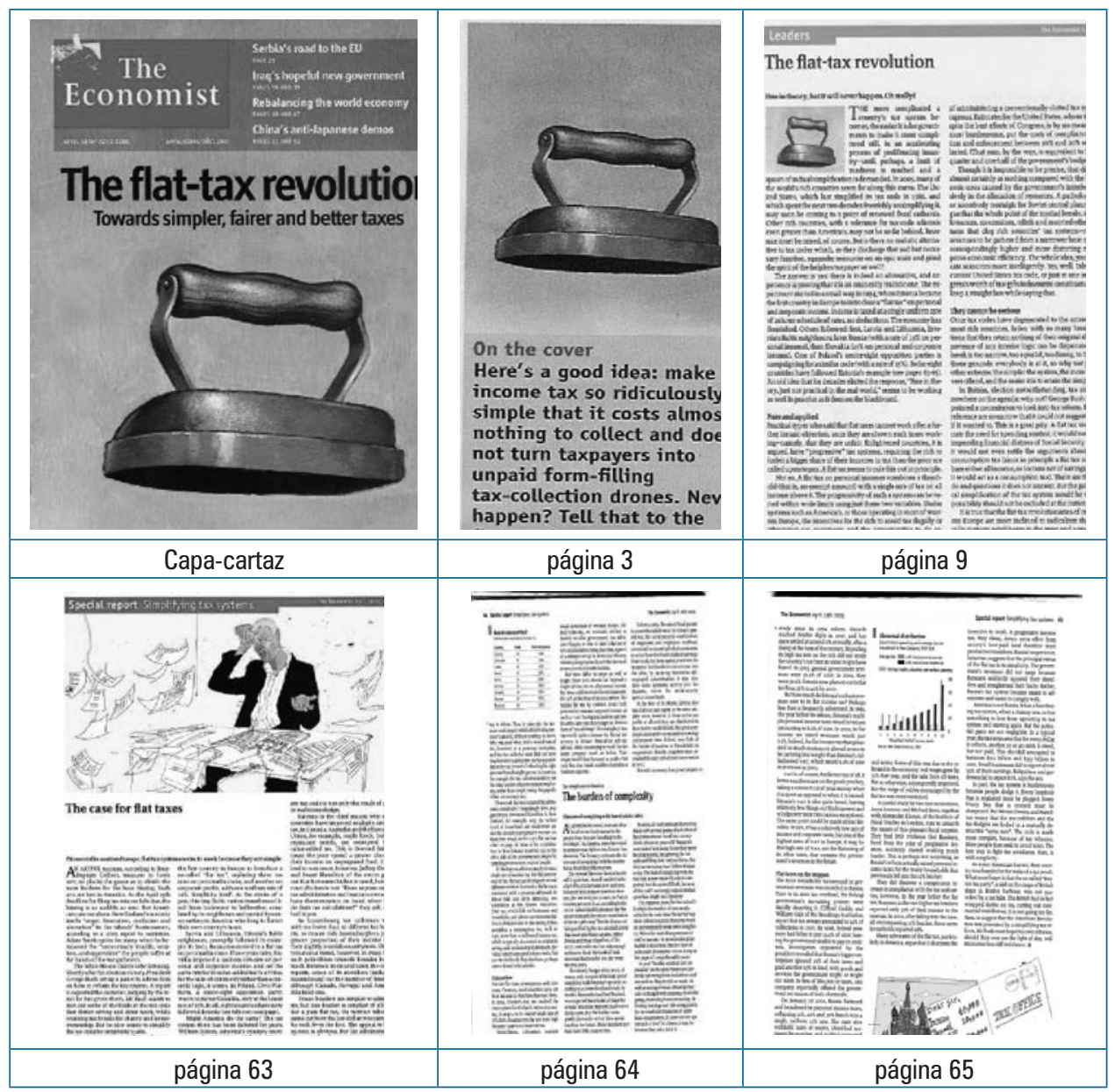


As estratégias enunciativas evidenciadas na notícia, caracterizadas ora por inversão, permuta, supressão, ora por interrupção, "são de natureza retórica, cujos aspectos estilísticos visam, sobretudo, alimentar a relação com o leitor, fixando ou captando a sua atenção, impressionando-o, comovendo-o, entusiasmando-o, chamando-o à participação, criando com ele um discurso sobre o mundo, a partir da sua dimensão fática”, como explica Marques (2008, p. 37).

Dos elementos paratextuais mais evidenciados no nosso corpus, destacam-se, como vimos a descrever, as imagens, as ilustrações, as caricaturas, e as tabelas e gráficos, em relação estrita com os títulos, os quais denunciam uma tendência distinta na representação do discurso econômico e empresarial nos semanários seleccionados.

Enquanto os semanários Visão e Sábado apresentam a notícia em blocos curtos de texto, intercalados com fotografias, muitas das quais sobredimensionadas, e/ ou imagens e gráficos onde predominam as cores vermelha e laranja na sinalética, e barras dos gráficos, a Time e a Newsweek evidenciam uma tendência distinta pela apresentação da notícia em blocos de textos mais longos, coadjuvados por ilustrações, caricaturas e/ou imagens, bem como pelo uso criativo de gráficos de barras, não expectável no discurso técnico empresarial.

Figura 3. Tecnologias discursivas dos semanários Sábado e Visão

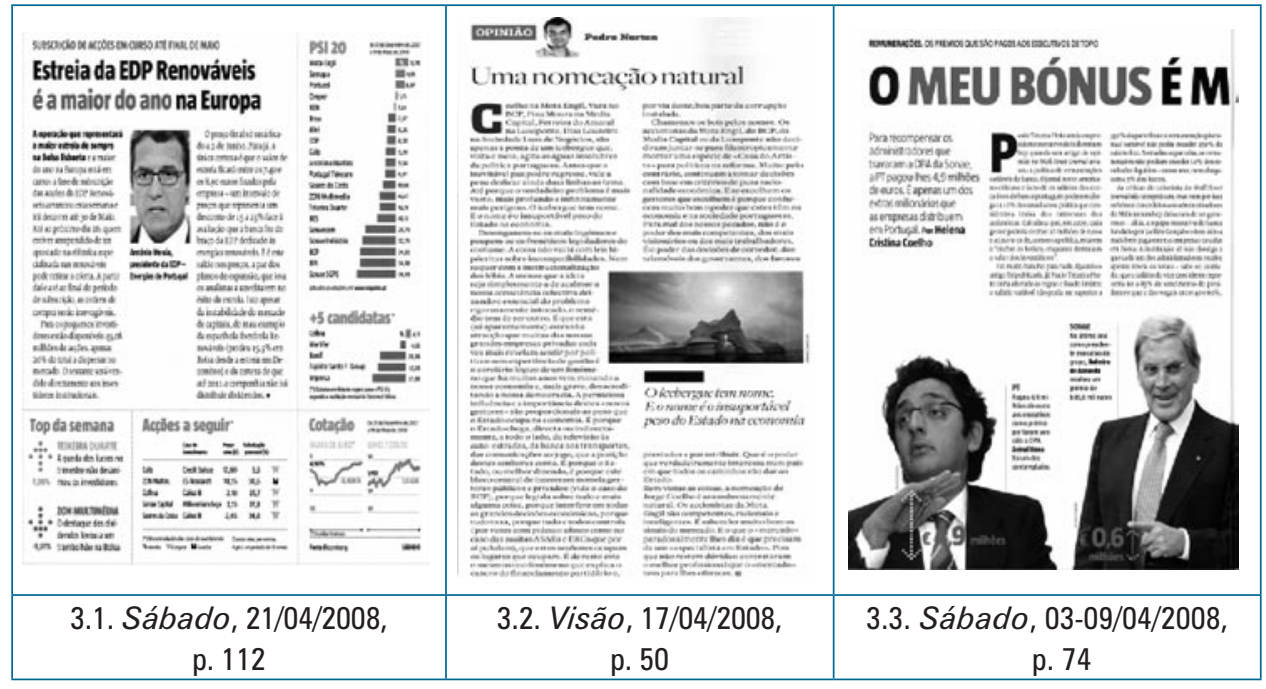

Relativamente às versões em português, destacamos as fotos de figuras públicas, predominantemente do sexo masculino, do domínio empresarial português, que surgem muito frequentemente no corpus em apreço. Simultaneamente, a ilustração gráfica tem uma dimensão maior em relação ao bloco 
de texto e nesta destacam-se "os olhos" (KRESS; LEEUVEN, 1999, p. 381), expressões faciais e o movimento das mãos ou mesmo o do dedo indicador, igualmente sobredimensionada. Nas imagens, o olhar dos participantes, ora é direccionado para os leitores (cf. Figuras 3.2. e 3.3.), estabelecendo-se um contacto directo, mesmo que seja no campo do imaginário, para citar Kress e Leeuven (1999), ora é direccionado para um dos ângulos da mesma (cf. Figuras 3.1. e 3.3.). Nestas últimas, está subjacente um certo distanciamento dos leitores/observadores em relação aos participantes, pelo facto de serem apresentados como se não estivessem a ser fotografados, observados, numa atitude defensiva. Pelo contrário, a figura pública, intencionalmente destacada no centro e canto inferior direito, onde o olhar do leitor se poderá fixar, parece convidar o leitor a "entrar numa relação de afinidade social" (KRESS; LEEUVEN, 1999, p. 382). De facto, o dedo indicador aponta para a percentagem de 0,6\%, prefigurando-se como a remuneração mais baixa auferida. Paralelamente, o olhar directo e o sorriso confiante do engenheiro Belmiro de Azevedo, empresário português de sucesso, tem força persuasiva. O ângulo frontal conota também o apelo a um envolvimento directo do leitor (KRESS; LEEUVEN, 1999, p. 394), como se: "what you see here is part of our world, something we are involved with". Podemos inferir, na linha de Kress e Leeuven (1999, p. 383), que as imagens, denominadas pelos linguistas por "images of demand" (Ibid., p. 381), parecem definir o público alvo, maioritariamente masculino, a identificar-se com o empresário de sucesso, sendo portanto classificadas, pelo seu força persuasiva, de "image act".

Quanto ao segundo caso (Figura 3.3), a configuração visual tem a função de criar uma forma visual de contacto directo, explícito, como se no plano da linguagem verbal existisse a referência à segunda pessoa do pronome pessoal, tal como é descrito por Kress e Leeuven (1999), “you”, explícita em "the flax-tax revolution".

1. s a uniform rate on the goods you buy, taking a constant cut of

2. same cut from the last dollar you earn that he took from the fir

3. c efficiency. The whole idea, you see, is to allocate resources

As linhas de concordância acima transcritas evidenciam a mudança de tom e ponto de vista por parte do narratário, pela alternância pronominal, da terceira pessoa para a segunda pessoa, como se se tratasse de um texto persuasivo (hibridismo textual), nomeadamente do domínio publicitário.

Em português europeu, poderá ser marcada pela segunda pessoa do verbo, designadamente "você", ou por "vós", dependendo do grau de formalidade, distanciamento, ou proximidade, não sendo, contudo, as últimas formas pronominais tão usuais neste género textual, verificando-se mais a narrativa na terceira pessoa. Na Figura 3.2. ("Uma Nomeação Natural”, p. 50), trata-se de um artigo de opinião, cujo tom crítico e reivindicativo, mas persuasivo, no modo discursivo lógico-argumentativo, é marcado a nível do enunciado, o 
que leva o leitor a tomar partido, a agir no plano simbólico. Verificamos, por exemplo, a alternância de focalização: “(...) desenganem-se os mais ingénuos e poupem-se os frenéticos legisladores do costume (...)” (terceira pessoa), contrastando com "(...) a nossa consciência colectiva (...)" / "(...) muitas das nossas grandes empresas privadas (...)” (primeira pessoa do plural que anuncia um "eu” colectivo, corporativo), “ (...) para mal dos nossos pecados, não é o poder dos mais competentes, dos mais visionários, ou dos mais trabalhadores (...)”. Diríamos que estamos perante a representação de diversas vozes na narrativa ${ }^{8}$ (cf. BAKHTIN, 1998), desde as das instituições que se cruzam no plano enunciativo, à do autor-narrador e à dos vários públicos: desde a do cidadão comum, à do público leitor especializado. O aspecto intersubjectivo do discurso, em tom dialogante (cf. HABERMAS, 1976), coadjuvado pela interacção da linguagem verbal e não verbal, contribui, igualmente, para a justificação da validade da problemática: a nomeação de uma figura pública, ironicamente descrita como "especialista em Estado", o que conota "o insuportável peso do Estado na economia”. O recurso a trocadilhos, uso criativo de expressões, familiares ao leitor mais erudito (por exemplo, da "sustentável leveza do ser" ao título "O icebergue tem nome: E o nome é o insuportável peso do Estado na economia”), metáforas visuais e ironia, num texto aparentemente de fácil compreensão, a nível sintáctico e lexical, torna-se complexo.

As relações de poder são implicitamente activadas a nível discursivo, quer pelo envolvimento emocional (sinestesia), quer por perguntas de natureza retórica subjacente ao modo discursivo lógico-argumentativo, ilustradas nos seguintes enunciados, (1) e (2) respectivamente:

(1) "make flat taxes more palatable to the social democrats" 9

(2) "E se, pelo mesmo preço de um utilitário, lhe oferecerem um carro familiar de sete lugares e com grande capacidade de carga? Proposta irresistível? Para muitas família sim e a Renault sabe-o bem e prepara-se para lançar o Logan MCV." 10

O recurso à linguagem não-verbal, à imagem gráfica, nomeadamente à caricatura, evidente no corpus seleccionado em inglês (cf. Figuras 4.1. e 4.2.), reflecte uma tendência satírica na cultura anglo-saxónica, principalmente a partir do século XVIII, perpetuada até à contemporaneidade, pela sua função informativa, pedagógica e satírica. Também pelo grotesco dos acontecimentos ou personagens a que alude, causando o riso, por isso de natureza mais imediata, a caricatura de uma figura humana satirizada, neste caso a de Fidel Castro (cf. Figura 4.2.), conduz o alocutário para o domínio da acção por simu-

8 A idéia de multivocalida está relacionada com o conceito de polifonia de Bakhtin.

9 "The flat-tax revolution", The Economist, de 14/04/2005, p. 50.

10 Parágrafo introdutório (lead) de "Renault 'low-cost'", Visão, de 17/04/08, p. 72. 
lação. Dirige-se a públicos mais vastos, tornando os assuntos menos complexos, de mais fácil acesso. Poderíamos inferir que a caricatura torna os assuntos e acontecimentos, e citamos Marques (2008, p. 38), "mais inteligíveis, isto é, disponíveis para um número incomensurável de interlocutores, de culturas diversas, com interesses e gostos heterogéneos”. Contudo, pode ser percepcionada negativamente, e citando Kress e Leeuven (1999, p. 385), em certos contextos, tais como o contexto português, em que o humor pode ser percepcionado por leitores "educados nos géneros visuais e linguísticos" em apreço, como forma de trivializar assuntos sérios, tais como os do domínio empresarial. Segundo a justificação dos linguistas, esta atitude está relacionada com a suposta falta de seriedade e objectividade na apresentação de temáticas.

Curiosamente, ao acedermos à notícia sobre a situação socioeconômica e política em Cuba, no suporte digital (cf. Figura 4.3.), a caricatura de Fidel Castro é substituída por uma foto que "oferece" (cf. KRESS; LEEUVEN, 1999, p. 381) ao leitor uma perspectiva do estado depauperado do país. O título metafórico e hiperbólico, "Hatfuls of dollars", na versão impressa (cf. Figura 4.2.), é omitido e, em primeiro plano, surgem três adolescentes, de costas viradas para a cidade, que se afastam do centro, percorrendo uma larga avenida, em estado de degradação visível, dada a falta de infraestruturas.

A imagem estabelece uma relação directa com o título da notícia, num contínuo intersemiótico, criterioso e intencionalmente reduzido aos sintagmas nominais "Cuba's economy: rich government, poor people". O título é construído a partir de uma rima infantil inglesa, "tinker, taylor, soldier, sailor, rich man, poor man, beggar man”. E a imagem demarca exactamente o fosso entre os detentores do poder econômico e a classe desfavorecida por uma massa de água azul. Os primeiros são metaforicamente representados, no plano visual, pela linha contínua branca de edifícios de dimensões irregulares, em plano de fundo, e os desprotegidos, em primeiro plano, que se aproximam mais do campo visual do receptor. Em relação às caricaturas (cf. Figura 4.1. e 4.2.), destacam-se: I) o "porquinho", que simboliza as poupanças individuais, neste caso ilícitas, pois escondem-se debaixo do chapéu, em interacção com a metáfora conceptual e hiperbólica, "hatfuls of dollars"; II) o "gato" que representa o enriquecimento dos indivíduos a partir de remunerações extra-salário. É oportuno referir que a metáfora expressa pelo sintagma genitival em inglês "fat cats bonus" ( $\rightarrow$ "bónus milionários") é largamente usada no discurso econômico e empresarial (314.000 ocorrências registradas no google), imbuída, todavia, de uma conotação negativa, sobretudo no discurso mediático.

Curiosamente, o texto sobre "Remunerações. Os prémios que são pagos aos executivos de topo", do seminário Sábado, já sumariamente abordado (cf. Figura 3.3.), menciona a lexia "bónus" no título, porém surge associado à metáfora conceptual, quando o substantivo "bónus" ocorre em posição de sujeito, ou complemento, ligado aos verbos "emagrecer" e "cair", nas frases: "Mas, se os resultados caírem, o bónus também emagrece.”; “(...) Paulo Azevedo viu o 
seu bónus cair quase $25 \%$ quando os resultados da empresa tombaram” (p. 76). A lexia "bónus" é desambiguada, na notícia, ora pelos hipónimos, "prémios", "remunerações", e "compensações", ora, pelos sintagmas nominais, "bónus concedidos", "prémios generosos", "remunerações mais modestas", "inconsciente sistema de bónus generosos", "chorudas compensações", "um extra ao pacote salarial", "prémio de desempenho" nos quais predomina a adjectivação e a ironia.

Figura 4. Tecnologias discursivas do semanário The Economist, em versões impressa e digital

\begin{tabular}{|c|c|c|c|}
\hline $\begin{array}{c}\text { “American } \\
\text { lawmakers take } \\
\text { aim at fat cats' } \\
\text { bonuses, and } \\
\text { other news" }\end{array}$ & 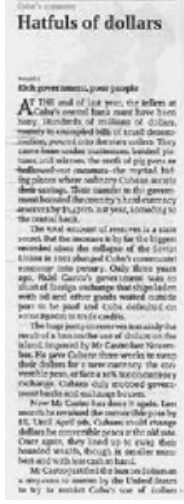 & 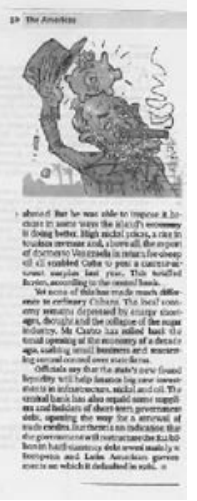 & 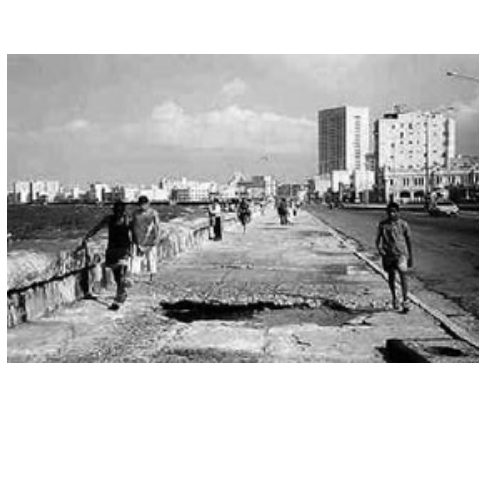 \\
\hline $\begin{array}{l}\text { 4.1. The Economist, } \\
\text { 23/03/2009. } \\
\text { Disponível em: } \\
\text { http://www. } \\
\text { economist.com/. } \\
\text { Acesso em: } 23 \text { mar. } \\
2009 \text {, às } 13 \mathrm{~h} 20\end{array}$ & \multicolumn{2}{|c|}{$\begin{array}{l}\text { 4.2. "Hatfuls of dollars", The } \\
\text { Economist, 16/04/2005, p. } 50\end{array}$} & $\begin{array}{l}\text { 4.3. "Rich government, poor people" In } \\
\text { The Economist, 16/04/2005. Disponível } \\
\text { em: http://www.hacer.org/current/ } \\
\text { Cuba046.php. }\end{array}$ \\
\hline
\end{tabular}

Refira-se que a leitura atenta dos exemplares dos semanários Sábado (03 / 04 / 2008) e Visão (03/04/2009; 17/04/2008; 26/06/2008), dos quais retiramos os excertos já mencionados, levou-nos a identificar uma larga ocorrência de neologismos e empréstimos, nos textos em português europeu. Para além do hiperónimo "bónus", já analisado, identificamos os empréstimos "subprime" (precedido de explicitação em português europeu), "mercado hipotecário de alto risco", "chairman", "performance" (e o termo equivalente "desempenho"), "cloudshopping", "know how", "speed dating" (seguido de explicitação, "rápida ligação em rede") ou usos criativos tais como: Renault 'low-cost', verão 'low-cost', encontros, speed networking, speed dating com cifrões, speed, agência de branding, empresas de private equity, grandes holdings, curso de taxiways, slots de saida. Verifica-se, portanto, uma tendência no discurso empresarial e econômico pelo recurso a 
vocábulos em língua inglesa, considerada a língua franca da contemporaneidade (SEIDLHOFER, 2004; JENKINS, 2006) e língua econômica (PHILLIPSON, 1996, 2002). O uso de anglicismos e lexias pode, no domínio discursivo empresarial e econômico em inglês, em textos em português, contribuir para a exclusão de leitores não educados nos domínios discursivos em foco.

Por outro lado, a identificação dos itens lexicais específicos do domínio empresarial e econômico, que ocorrem nos textos em inglês em estudo, possibilitou-nos concluir que mais de $50 \%$ dos itens lexicais são de origem latina e largamente usados na comunicação global.

Ainda na linha da abordagem dos elementos que suscitam a adesão do leitor, a nível da interacção da linguagem não-verbal e verbal em relação (GOODMAN, 1996, p. 69) e a nível da semiótica discursiva, salientamos o recurso a gráficos, mapas, diagramas e tabelas, muitos a cores, em textos no domínio interdiscursivo: empresarial e econômico e mediático. Embora este tipo de representação gráfica seja mais frequente em contextos onde se dá a primazia do conhecimento objectivo, imparcial e desprovido de envolvimento emocional (KRESS; LEEUVEN, 1999, p. 384), verificamos que os textos seleccionados em versão portuguesa, entre muitos de um corpus mais vasto nos semanários em apreço, apresentam uma forte tendência para o uso criativo de várias formas de representação gráfica de dados, suscitando a adesão do leitor (cf. Figura 5.1., "A temperatura da bolsa”).

Fomentam uma leitura dinâmica, interactiva, e redireccionam a atenção do narratário, um público mais vasto, para a interpretação de tabelas, gráficos e diagramas (frequentemente sobredimensionados nas páginas dos semanários em versão portuguesa), porém desmistificando o grau objectivo e tecnicista da comunicação empresarial e de negócios. Partindo de conteúdos e referências familiares, bem como de diversos tipos de textos mais comuns na comunicação interpessoal (cf. HALLIDAY; HASAN, 1993; GOODMAN, 1996, p. 184), o locutor introduz novos e inesperados significados ("estranhamento"), levando o narratário a aderir ou recusar o conteúdo proposicional. Consequentemente, e citando Goodman (1996, p. 184), "ao familiar é dado um sentido de novidade devido ao conteúdo da mensagem com preocupações estilísticas a ser desambiguada em contexto" [tradução nossa]. 
Figura 5. Interacção da linguagem verbal e não-verbal: coerência intersemiótica

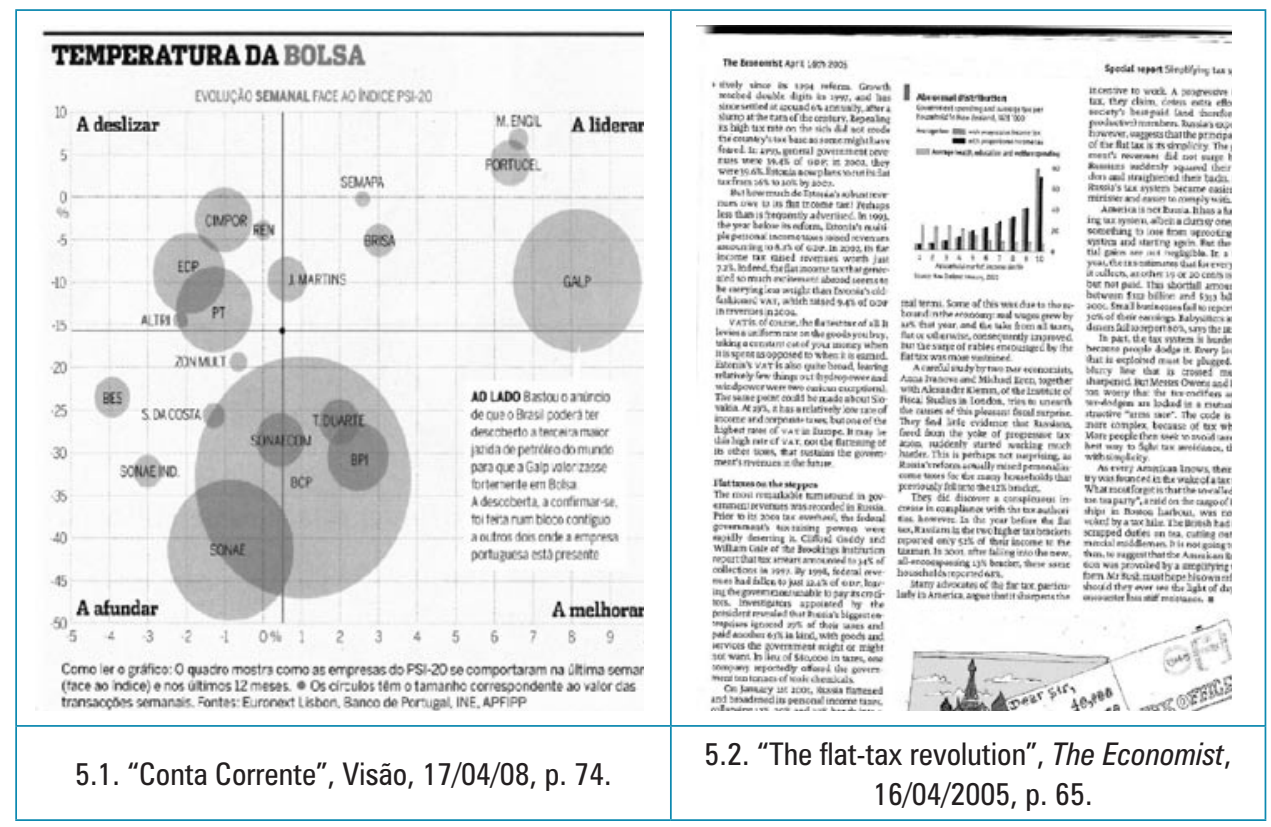

Atentemos, mais uma vez, na reportagem mencionada anteriormente sobre a política de impostos e as vantagens da taxa única (cf. Figura 5.2, "The Flat tax revolution”). Observamos, por exemplo, a inserção inesperada, ou mesmo descontextualizada, de um postal coadjuvado por uma contabilização de impostos, cujo destinatário é, ironicamente, a própria repartição de finanças, na secção de impostos. Simultaneamente, deparamo-nos com a discussão de dados objectivos, sintetizados na representação gráfica (através do gráfico de barras), com base em fontes fidedignas, relativos à distribuição anormal dos gastos do governo e os impostos pagos em média por agregado familiar na Nova Zelândia. Os subtítulos, "Fine in theory but it will never happen. Oh really?" e "the costs of complying with America's tax rules", procuram levar o leitor a identificar-se com a problemática dos impostos. Para tal, a pergunta retórica, verbalizada no subtítulo "How simple can it be?", visa guiar o interlocutor através de próprio raciocínio do narrador, num modo lógico-argumentativo, implícito no subtítulo "Simplifying tax systems", e marcado pela forma do gerúndio, pressupondo a sua participação no contexto político e econômico.

\section{Coerência intersemiótica}

No âmbito da interacção do leitor com a linguagem do texto multimodal é pertinente citar Lier (1996, p. 53), que se refere não só à apreciação intuitive, mas também ao seu envolvimento estético: " with rich variety of exposure- 
language [and] sufficient means of access (e.g., comprehension, familiarity, assistance) for the perceived material to activate cognitive networks, thus creating the possibility for linking interaction and cognition [for example, schema refreshment or schema reinforcement]." O envolvimento do leitor com o texto multimodal é reforçado pela busca da coerência intersemiótica entre o signo verbal e o não-verbal, visual, do familiar para o desconhecido, subjacente à interpretação do texto de uma forma particular. Por outras palavras, estas escolhas linguísticas e discursivas a nível textual, e corroborando a argumentação de Pedro (1997, p. 294), são estratégias que "revelam não apenas o posicionamento do autor relativamente à história real" - neste caso, o assunto ou o tópico, que "justifica a informação - mas, também, as estratégias que usa para posicionar, de modo particular, os seus leitores.”

Os textos multimodais seleccionados permitem-nos concluir que estabelecem uma ordem que é partilhada pelo leitor, como se cada signo verbal e nãoverbal, a palavra e a imagem gráfica, surgissem num contínuo significativo e não, citando o argumento de Zink (1999, p. 1), "uma sobreposição da imagem em relação à linguagem verbal.” Por outras palavras, o que é distintivo neste domínio interdiscursivo, corroborando Zink (1999, p. 20), "é a interacção dinâmica, não reiterativa nem pleonástica, entre elementos oriundos de um código verbal e um código icónico, constituindo-se num só e novo código. O que implica um novo modelo de leitura e de contacto com o leitor."

Os textos seleccionados parecem mediar autoridade (ethos) numa alternância dinâmica entre persuasão, ora de uma forma implícita, ora explícita, e informação. Na linha do discurso polifónico defendido por Bakhtin, conclui Conceição (2008, p. 21), o discurso próprio empresarial é apropriado pelos jornais, "retrabalhado e reacentuado de acordo com o lugar da interlocução que pretendem ocupar e atribuir aos outros. Nesse movimento das identidades, pode-se perceber o trabalho ideológico e estruturante do discurso, gerando representações, impondo visões e divisões." Trata-se de um padrão de organização da informação utilizado na narrativa jornalística, o qual visa informar, fomentando a aquisição de conteúdos (conteúdo proposicional - "factos"), através da activação de referências socioculturais, familiarização do leitor com uma complexidade de conceitos nos domínios técnicos/especializados, todavia impondo um ponto de vista.

Para além do tom dialogante implícito, tanto nos títulos e subtítulos, como nas escolhas linguísticas já sumariamente abordadas, que constitui um dos aspectos apontados por Fairclough (1992) (característicos do envolvimento do leitor com o potencial significativo dos modos representativo e comunicacional em domínios discursivos), referimos, ainda, o recurso às metáforas visuais, algumas das quais implícitas nos idiomatismos. Estes surgem, ora em contextos inesperados para o leitor leigo, ora associados a referências extratextuais, potencializando as conexões entre os blocos de texto e facilitadores da interacção do público leitor com lexias especializadas. São veiculados em discurso directo, para marcar o 
distanciamento do autor, como garantia da veracidade dos factos, porém, constituem uma perspectiva sobre temáticas recorrentes no domínio empresarial e econômico. Afinal, idiomatismos como "Foi muito barulho para nada."11 (Sábado, 09/04/2008, p. 74) ou "at the stroke of a pen" (The Economist, 16/04/2005, p. 63), desencadeiam o processamento cognitivo de metáforas e esquemas conceptuais para activação das funções comunicativa e estética.

A caricatura de uma figura humana, masculina, que precede a notícia "Simplifying tax systems" (The Economist, 16/04/2005, p. 63-65), demonstra o impacto do imediatismo das imagens (LEWIS, 2001, p. 94), as quais, em interacção com a linguagem verbal, criam efeitos narrativos específicos. A linguagem não-verbal evidencia, e citando Koller (2004, p. 172), "modelos conceptuais de agressividade e competição", nomeadamente pelo franzir das sobrancelhas, o movimento das mãos, num misto de preocupação e crispação, bem como a direcção do olhar da figura masculina para as inúmeras folhas dispersas, esvoaçando, pela mesa. Esta imagem alude não só a atitudes e emoções, mas também à forma como a informação sobre o preenchimento dos impostos constitui um fardo para os contribuintes (WALES, 1997, p. 271).

A metáfora visual do contribuinte em apuros com o preenchimento dos impressos dos impostos é antecipada no tipo de descrições que a precedem a nível textual, "The burden of complexity" (Economist, 16/04/2005, p. 64), e reiteram a imagem associada aos contribuintes, por exemplo na página 3, "unpaid formfilling tax collection drones". Também a metáfora da guerra/luta (KOLLER, 2004, p. 172), associada ao mundo dos negócios, é explicitada noutro texto da reportagem especial, que precede a imagem, em que o narratário é envolvido: "But Americans are not alone. New Zealand's tax code instills "anger, frustration, confusion and alienation" in the islands' businessmen, according to a 2001 report to ministers"; "squander resources on an epic scale and grind the spirit of the helpless taxpayer." (Economist, 16/04/2005).

Figura 6. Estereótipos da figura masculina (The Economist, 16/04/2005, p. 63)

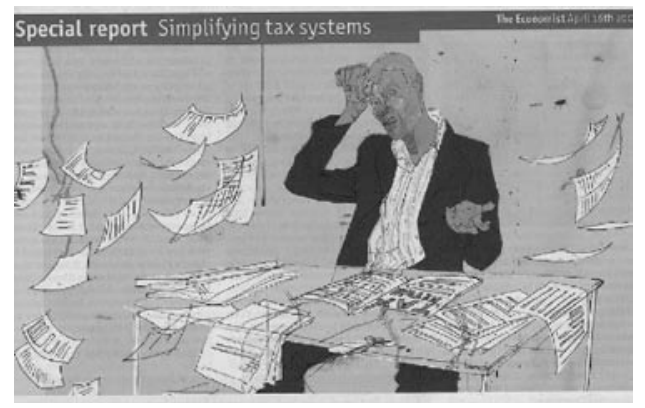

11 Embora a expressão seja usual em português, e do domínio coloquial, assemelha-se à expressão em inglês, "Much ado about nothing", título de uma das comédias de Shakespeare. 
De facto, a figura central em apuros enquadra-se no tipo de modelos conceptuais estereotipados, na acepção de Koller, caracterizado pela competição agressiva no contexto empresarial, ao qual pertencem muitos dos leitores das revistas ou artigos dos jornais econômicos. Parece plausível, pois, no entender de Koller (2004, p. 174), que os jornalistas imitem e projectem, de uma forma inesperada, o modelo cognitivo já percepcionado pelos leitores. Assim sendo, este tipo de metáfora não só contribui para manter o interesse pela revista (Ibid., p. 178), mas também promove entretenimento enquanto informa, forma e conduz ao agir comunicativo.

\section{Conclusão}

Nos textos seleccionados da revista The Economist, Sábado e Visão, referentes a comunidades interdiscursivas, que apresentam aparentemente uma linguagem denotativa, sobretudo para fins informativos, pudemos constatar a dimensão significativa (KRESS, 1997, p. 382; KRESS; LEEUVEN, 2001, p. 91), designadamente as funções referencial, interpessoal e composicional. Estas são veiculadas a nível estrutural pelo recurso a uma língua franca e a estratégias linguísticas e estilísticas frequentes. Todavia, não podemos deixar de analisar as escolhas linguístico-discursivas nos e para além dos textos, no contexto discursivo e social. Por um lado, permite-nos percepcionar as estratégias conducentes ao envolvimento dos leitores / cidadãos na construção de sentidos (especialistas e leigos) e, subscrevendo Pedro (1997, p. 306), "directa ou indirectamente, influenciar a forma como a mensagem veiculada é recebida, interpretada e interiorizada pelo público consumidor." Referimo-nos ao emissor, no plano enunciativo, e o modo como se demarca do estilo característico do discurso jornalístico e da própria instituição. Por outro lado, contribui para um maior entendimento das representações, por vezes estereotipadas, do discurso empresarial em textos multimodais nos media, que reflectem modos discursivos. Por outras palavras, constatamos a voz do sujeito colectivo na comunidade discursiva em que se inscreve, isto é, o domínio empresarial e econômico.

A abordagem multidisciplinar promove uma leitura e escrita críticas pela análise da língua em uso na construção de sentidos para um entendimento do entrosamento de comunidades discursivas (discurso empresarial econômico/político e mediático). A análise de níveis de significação, proposta pela estilística aplicada, permitiu-nos percepcionar a dimensão social do discurso empresarial (SANTOS, 1996), ao veicular géneros discursivos e modos de interacção como constantes estruturais (REX, 2001). De facto, o enfoque em excertos dos semanários, em versões portuguesa e inglesa, revelou que existem aspectos comuns no estilo jornalístico, relativamente à representação do discurso empresarial, norteados pela organização dos modos discursivos, no sentido de narrar, descrever e clarificar. Existe uma relação entre a imagem gráfica e as coordenadas textuais, o que permite ao leitor uma maior interacção com o potencial da narrativa, com a denotação e com a conotação. A utilização de uma língua franca disseminada 
em textos multimodais nos domínios empresarial e econômico nos media facilita a participação dos cidadãos na economia e política a nível global.

Os textos multimodais permitem ao leitor interagir com linguagens diversificadas, pelo envolvimento com estímulos visuais, auditivos e verbais. Quer a caricatura, ou metáfora visual, mais evidente no caso dos semanários em língua inglesa, quer a imagem, predominante nos exemplares em língua portuguesa, apontam para o domínio empresarial e de negócios como um contexto de competitividade, em que os cidadãos estão à mercê das tomadas de decisão no âmbito do discurso empresarial, ilustrada, por exemplo, na seguinte metáfora "so plucks the goose as to obtain the most feathers for the least hissing" (The Economist, 16/04/2005, p. 63), ou "um sinal de que a política de prémios milionários nas empresas está para durar" (Sábado, 03/04/2008, p. 77). No entanto, a função referencial, informativa, parece estar mais relacionada com o plano da imagem (HALLIDAY, 1994), de cariz mais imediato, e do verbal com o do comentário.

Com o enfoque em representações do discurso empresarial em textos multimodais nos media esperamos ter demonstrado o benefício de uma análise multidisciplinar, no sentido de desambiguar aspectos relacionadas com a retórica visual e os mecanismos linguísticos e estilísticos, como mecanismos de persuasão do receptor.

\section{Referências}

BAKER, Paul. Using corpora in discourse analysis. Nova lorque: Continuum, 2006.

BIBER, Douglas; CONRAD, Susan; REPPEN, Randi. Corpus linguistics: investigating language structure and use. Cambridge: Cambridge University Press, 1998.

CAMERON, Deborah et al. Power/knowledge: the politics of social science. In: JAWORSKI, Adam; COUPLAND, Nikolas (eds.). The discourse reader. Londres/Nova lorque: Routledge, 1999. p. 141-157.

CARRILHO, Manuel Maria (Org.). Retórica e comunicação. Porto: Edições Asa, 1994.

CARTER, Ronald; LONG, Michael. Teaching literature. Londres: Longman, 1991.

CARTER, Ronald; NASH, Walter. Seeing through Language: a guide to styles of English writing. Londres: John Wiley \& Sons, 1991.

CARTER, Ronald; McRAE, John. Teaching Literature: a view for the 90s. Greta, Granada, v. 2, p. 5-10, dez. 1994.

CARTER, Ronald; SIMPSON, Paul. Language, discourse and literature: an introductory reader in discourse stylistics. London: Routledge, 2004.

CLARK, Urzsula; ZYNGIER, Sonia. Towards a Pedagogical Stylistics. Language and Literature (Journal of the Poetics and Linguistics Association), Londres, v. 12, n. 4, p. 339-351, 2003.

CONCEIÇÃO, Francisco (Org.). Entrevozes: enredos institucionais e midiáticos. São Luís: EDUFMA, 2008.

FONSECA, Joaquim. Linguística e texto / discurso, teoria, descrição, aplicação. Lisboa: ICALP, Ministério da Educação, 1992.

FAIRCLOUGH, Norman. Discourse and social change. Cambridge: Polity Press, 1992. What might we mean by enterprise discourse? In: Critical discourse analysis: the critical study of language. Londres/Nova lorque: Longman, 1995. . Discurso, mudança e hegemonia. In: PEDRO, Emília Ribeiro. Análise crítica do discurso. Lisboa: Editorial Caminho, 1997. p. 77-103.

FOUCAULT, Michel. Power/Knowledge: selected interviews and other writings, 1972-1977. Edited by Colin Gordon. Nova lorque: Pantheon Books, 1980.

. A ordem do discurso: aula inaugural no Collège de France, pronunciada em 2 de dezembro de 1970. São Paulo: Edições Loyola, 1996. 
GENETTE, Gérard. Paratext: thresholds of interpretation (literature, culture, theory). Cambridge: Cambridge University Press, 1997. GOODMAN, Sharon. Visual English. In GOODMAN, Sharon; GRADDOL, David. Redesigning English: new texts, new identities. Londres: Routledge, 1996. p. 38-105.

GOODMAN, Sharon; GRADDOL, David. Redesigning English: new texts, new identities. Londres: Routledge, 1996.

HABERMAS, Jürgen. Legitimation and crisis. Londres: Heineman, 1976.

HALLIDAY, Michael; HASAN, Ruqaiya. Language, context, and text: aspects of language in a social-semiotic perspective. Victoria: Deakin University Press, 1993.

HOEY, Michael. Textual interaction: an introduction to written discourse analysis. Londres: Routledge, 2001. . Lexical priming: a new theory of words and language. Londres: Routledge, 2005.

HOLQUIST, Michael (Ed.). The dialogic imagination: four essays by M. M. Bakhtin. Austin: University of Texas Press, 1998.

JAKOBSON, Roman. Linguistics and poetics. In: SEBEOK, T. (Ed.). Style in language. Cambridge, Massachusetts: MIT, 1960. p. 350-377.

JENKINS, Jennifer. World englishes. Londres: Routledge, 2003.

JERECZEK, Joanna. La référenciation au sein du récit médiatique: l'ímagé de l'économie. In: KESIK, Marek (Ed.). Référence discursive dans les langues romanes et slaves [Actes du troisième colloque international de linguistique textuelle]. Lublin, Polónia: Wydawnictwo Uniwersytetu Marii Curie-Skłodowskiej, 2002. p. 93-105.

KJ/ER, Peter; SLAATTA, Tore (Eds.). Mediating Business: the expansion of business journalism. Copenhagen: Copenhagen Business School Press, 2007.

KOLLER, Veronika. Metaphor and gender in business media discourse. Hampshire: Palgrave Macmillan, 2004.

KRESS, Gunther; HODGE, Robert. Multimodal texts and critical discourse analysis. In: PEDRO, Emília (Ed.). Proceedings of the first international conference on discourse analysis. Lisboa: Edições Colibri, 1997. p. 367-383.

KRESS, Gunther; LEEUVEN, Theo. Multimodal discourse: the modes and media of contemporary communication. London: Arnold, 2001.

. Representation and interaction: designing the position of the viewer. In: JAWORSKI, Adam; COUPLAND, Nikolas (Eds.). The discourse reader. Londres/Nova lorque: Routledge, 1999. p. 377-404.

Reading images: the grammar of visual design. Londres/Nova lorque: Routledge, 2006.

LIER, Leo van. Interaction in the language curriculum: awareness, autonomy, and authenticity. Londres: Addison Wesley, 1996.

LEWIS, David. Showing and telling: The difference that makes a difference. Reading: literacy and language, 0xford, v. 35, n. 3 , p. 94-98, nov. 2001

MACLEOD, Norman. Stylistics and point of view in fiction: A credo and some examples. The European English Messenger, Londres, v. 14, n. 2, p. 71-73, 2005.

MAINGUENEAU, Dominique. Novas tendências em análise do discurso. Tradução e revisão: Adagoberto Batista. Campinas: Unicamp / Pontes Editores, 1997.

MARQUES, Ester. Estruturas do discurso jornalístico. In: CONCEIÇÃO, Francisco (Org.). Entrevozes: enredos institucionais e midiáticos. São Luís: EDUFMA, 2008. p. 25-41.

MIELNICZUK, Luciana; PALACIOS, Marcos. Considerações para um estudo sobre o formato da notícia na Web: o link como elemento paratextual. Disponível em: <http://www.ufrgs.br/gtjornalismocompos/doc2001/palacios_mielniczuk2001. rtf. >. Acesso em: 04 abr. 2009, às 10h39.

PARTINGTON, Alan. Patterns and meanings: using corpora for English language research and teaching. Filadélfia: John Benjamins, 1998.

PEDRO, Emília Ribeiro. 0 discurso dos e nos media. In: . Análise crítica do discurso. Lisboa: Editorial Caminho, 1997. p. 293-312.

PHILLIPSON, Robert. English-only Europe? Challenging language policy. Londres/Nova lorque: Routledge, 2003.

REX, Lesley. The Remaking of a high school reader. Reading Research Quarterly, v. 36, n. 3, p. 288-314, 2001.

SAMPSON, Geoffrey; McCARTHY, Diana (eds). Corpus linguistics: readings in a widening discipline. Londres: Continuum, 2004. SANTOS, Boaventura de Sousa. Um discurso sobre as ciências. 8. ed. Porto: Edições Afrontamento, 1996.

SEIDLHOFER, Barbara. English as a Lingua Franca in the expanding circle: what it isn't. In: RUBDY, Rani; SARACENI, Mario (Eds.). English in the world. Global rules. Global roles. Londres: Continuum, 2006.

SINCLAIR, John. Trust the Text: Language, Corpus and Discourse. Londres/Nova lorque: Routledge, 2004.

SHORT, Mick. "Where are you going to my pretty maid" "For detailed analysis, sir", she said. In: STOCKWELL, Peter; LAMBROU; Marina (Eds.). Contemporary stylistics. Londres: Continuum, 2007.

VERDONK, Peter (Ed.). Twentieth century poetry: from text to context. Londres/Nova lorque: Routledge, 1993.

WALES, Kathy. Dictionary of stylistics. Essex: Edinburgh, 2001.

ZINK, Rui. Literatura gráfica? Banda desenhada portuguesa contemporânea. Oeiras: Celta, 1999. 